\title{
Insiders say NICE is being encouraged to be more favourable to industry
}

\author{
Deborah Cohen
}

The BMJ

Committees of the UK National Institute for Health and Care Excellence (NICE) are being encouraged to be more favourable to the drug and device industries, The $B M J$ has been told.

The concerns have been raised since a change in the minister with responsibility for NICE. On 15 July this year George Freeman took over this role when he was appointed as parliamentary undersecretary of state for life sciences at the Department for Business, Innovation and Skills and the Department of Health for England. It is a new ministerial post with a remit to accelerate innovation.

NICE sources are concerned that the change in minister responsible for the institute could lead to greater pressure to allow doctors to prescribe drugs before NICE has appraised them. The sources also told The BMJ they were worried about pressure to be more lenient in the interpretation of evidence.

In the past the minister with responsibility for NICE has sat within the medicines and pharmaceutical industry branch of the Department of Health. The previous holder of the post was the peer Lord Howe.

James Raftery, professor of health technology assessment at Southampton University, told The BMJ that there were risks attached to the new appointment. "The new minister having joint responsibility to BIS [Department for Business, Innovation and Skills] as well as the Department of Health runs the risk of giving greater weight to industrial policy within health policy," he said. "This, I fear, would impose costs on the NHS.

Promotion of innovation is a matter for industrial policy rather than the NHS. The NHS Constitution emphasises that the function of the NHS is to provide appropriate healthcare to all who need it without payment."

Freeman's other responsibilities will include the Medicines and Healthcare Products Regulatory Agency and the Cancer Drugs Fund, and he will be responsible for a new scheme involving the uptake of new drugs and medical technology, including adaptive licensing and early access. The scheme is, said Freeman in a House of Commons debate on 1 September, a "new fast track runway to get a new generation of innovative medicines to the patients for whom there is no alternative treatment, to give them a chance and some hope that their suffering might help to prevent suffering for future generations.'

Before becoming a Conservative MP Freeman had a long career in biomedical venture capital and ran the specialist translational medicine consultancy 4D Biomedical. He was also chief executive officer of the Cambridge start-up company Amedis
Pharmaceuticals and before that the director of early stage ventures at the venture capital fund Merlin Biosciences.

Sources say it is as yet unclear how he will interact with NICE. In September this year Freeman told the Commons debate that it was "vital" for people to have access to new and promising drugs. "In drug discovery, time is money, and accelerating assessment and approval is the single most important reform that we have to make. I am absolutely committed to it," he said. Freeman said he has already met with NICE's chief executive and chair to highlight his concerns.

He also told the Commons he wanted a "conversation about the new model for NICE." He said, "The rapid development of breakthroughs in genomics, informatics, and new diagnostics means that NICE's processes will have to adapt. Since it was established in 1999 NICE's internationally renowned technology appraisal process has evolved constantly to meet new challenges. I am confident that it will continue to do so-it will need to if it is to keep its place at the vanguard of international health technology assessment."

He added, "A central part of my mission as the UK's first minister for life sciences - an opportunity that reflects the government's commitment and the prime minister's personal commitment to this agenda-is to accelerate the discovery, design, and adoption of new drugs in the NHS, making the UK the best place in the world to discover and design 21 st century healthcare technologies."

Andrew Dillon, NICE's chief executive, commented, "This recent change in ministerial accountability leaves NICE's functions unchanged but provides a greater opportunity for us to engage with and influence the development of a more productive relationship between the life sciences industries and the NHS."

An advertisement appeared in the Sunday Times this week to appoint a non-executive director at NICE from the life sciences industry. The advertisement said that the role of NICE's board during the current three year strategic planning included "maintaining NICE as the primary standard-setter in healthcare, public health practice and social care" and to "work with industry and the Government to help promote sustainable growth in the life sciences industries." The new appointment will have to sign NICE's strengthened conflict of interest policy, updated in September. 
(c) BMJ Publishing Group Ltd 2014 